\title{
ANALYSIS ON CLASSIFICATION OF FOOTBALL TECHNIQUE
}

\author{
Kristaps Slaidin̄̌s \\ Latvian Academy of Sport Education, Latvia \\ Andra Fernāte \\ Latvian Academy of Sport Education, Latvia
}

\begin{abstract}
Football is a situation sport where football players are characterized by a great variety and complexity of activities during the game, both in contact with the opponent and in the immediate vicinity of the opponent, while cooperating with other teammates. Sports scientists and coaches need to find out more about the set of techniques, its diversity and the amount of technique in top level football games in order to guide the optimal planning and implementation of the training process in the technical training of football players. Due to the diversity of techniques used by football players, there are different approaches to the classification of these techniques. However, it is very important to group all techniques according to their common features in order to adequately assess the structure of a football game, its development tendencies and issues. Research aim: to compare and analyse the essence of the classification of football technique and its development tendencies. Research methods: analysis of scientific articles (electronic scientific databases ScienceDirect, Google Scholar), search keywords - football, football technique, classification of football technique. Main results of the research: two main approaches dominate in the classification of football technique: the technique approach and the game approach. Initially, football technique was mainly grouped by taking into account the player's actions with or without the ball, the level of difficulty of the technique element, the role of the players and the player's actions on the spot or in motion. As football develops, football technique is classified by taking into account the effectiveness of its application in specific tactical situations.
\end{abstract}

Keywords: classification of football technique, football, football technique.

\section{Introduction}

The analysis of the classification of football technique is important for sport specialists to research about the set of techniques, its diversity and the amount of technique in top level football games in order to guide the optimal planning, implementation of the training process and qualitative assessment in the technical training of football players. Classification is a logical analytical operation, where phenomena are divided into groups and subgroups according to their common or similar features, while the basic elements of each classification are their 
theoretical connection, basic elements and criteria. There are two different and significantly diverse types of classification, those that reflect structural organization and those that systematically reflect historical developments. Sports can be classified, for example, according to type and intensity: football is characterized by low static and high dynamic (Mitchell et al., 1994) and football is an intense multi-directional and intermittent field sport (Lupo et al., 2019). The main purpose of classification is to describe the structure and connections of similar object groups, as well as the achievement of practical goals (Sokal, 1974), for instance, a computerized data specification for classification to improve objectivity, for example, to study pass properties that may affect classification and then apply the developed classification to obtain quantitative measurements of performance (Horton et al., 2014).

The view on the use of the term "technique" in the scientific literature in sport is very often not precisely defined, while the notion of "technique" has a diverse meaning. Very often this term is taken for granted and, therefore, it is very difficult to describe and express it in measurable terms. Already in 1982, N. Ozoliņš has defined technique as the most rational and efficient execution of movements in order to achieve the highest results. However, in 1983, technique is defined in sports games as a movement or part of a movement, which purposefully allows to perform actions in attack or defence with sufficient quality during the game, taking into account the ideal model (Bös \& Mechling, 1983). The most common definitions of "technique" in scientific literature do not indicate how a "technique" can be measured, but at the same time characterize "technique" with variables that can be visually perceived (Lees, 2002). Technique can also be described as any sport skill that has a certain way of solving a movement task (sport skill content) in accordance with the rules of the respective sport, the athlete's biomechanical conditions and movement possibilities (Zahradník \& Korvas, 2017). Thus, movements can be classified according to their purpose (Bartlett, 2014).

Qualitative assessment of movements requires that professionals are able to simultaneously integrate a wide range of information on the technical performance of athletes, as well as have sufficient knowledge of the athlete and his/her movements in context (Knudson, 2013), as a player's performance in football is determined by technical and tactical skills (Bangsbo, 1994). Technical skills include the player's actions on the field without the ball (locomotive action) and with the ball in a certain position on the field (Andersson et al., 2008; Bradley et al., 2007, 2011). Qualitative assessment of movements involves the identification of all factors that affect an athlete's performance and the determination of the most important influencing factor in order to further improve an athlete's performance (Knudson, 2013), as in practice football players need to promote a wide arsenal of technique, which could be used during the game 
SOCIETY. INTEGRATION. EDUCATION

Proceedings of the International Scientific Conference. Volume IV, May $28^{\text {th }}-29^{\text {th }}$, 2021. 456-467

(Esposito et al., 2019). A skilled football player is able to manage a larger number of possible technical-tactical actions in a shorter time and is able to choose the most optimal possible variants of technique application during the game (Gonzalez-Villora et al., 2015).

Research aim: to compare and analyse the essence of the classification of football technique and its development tendencies.

\section{Research Methodology}

In order to compare the essence of the classification of football technique and its development tendencies, a systematic search and review (Booth, Sutton, \& Papaioannou, 2016) of scientific articles was conducted in two electronic databases of scientific literature - Science Direct and Google Scholar. The inclusion criteria for study selection: the article was written in Latvian, English, Russian. Keywords used for the search - football, football technique, football technique classification (Andersson et al., 2008; Bradley et al., 2007, 2011) in the previously mentioned languages. The period covered by the research is from 2000 to 2020. The search process was repeated nine times, using each keyword. As a result, 11 sources were analysed in depth.

\section{Research Results}

\section{Literature search}

Databases: Science Direct (SD), Google Scholar (GS)

Inclusion criteria: articles in Latvian (LV), English (EN) and Russian (RUS) only

1. No. of records identified through the search "football" (GS)

$(n=136(L V), n=1970000(E N), n=107000$ (RUS)

2. No. of records identified through the search "football technique" (GS)

(n= 69 (LV), n=931 000 (EN), n=15 500 (RUS)

3. No. of records identified through the search "football technique classification" (GS) (n= 31 (LV), n= 135000 (EN), n= 8600 (RUS)
1. No. of records identified through the search "football" (SD)

(n= 0 (LV), n=26 293 (EN), n= 0 (RUS)

2. No. of records identified through the search "football technique" (SD) (n= 0 (LV), n= $15171(\mathrm{EN}), \mathrm{n}=0$ (RUS)

3. No. of records identified through the search "football technique classification" (SD) (n= 0 (LV), n= 4209 (EN), n= 0 (RUS)

Figure 1 The Process of Systematic Search (by the Authors) 
The results of the research show that the majority of the information in the Science Direct and Google Scholar databases in the field of football is available in English n=1 996 293, using the keyword "football” (see Fig. 1). Moreover, by entering the keyword "football technique", the amount of available information already decreased by $n=1050122$ units. Furthermore, by entering the keywords "football technique classification", the amount of available information further decreased by $n=910913$ units.

When evaluating the articles in the databases by using the keywords "football technique classification", identical articles were identified, which were not considered further, as well as the types of technique classification were repeated in most articles. Therefore, 11 articles were selected for further analysis.

The selected research in the Science Direct database mainly reflect the classification of football technique in action with the ball. The aim of the first research (Zambom-Ferraresi, Rios, \& Lera-Lopez, 2018) was to show that computer driven mathematical and recent statistical modelling methods employing past statistics data can be used to provide European football teams' managers with additional information to improve their hiring decisions (Table 1). Based on the results of the research, it can be concluded that football technique can be classified by effectiveness as a feature and that football player movements in attack are more important than player movements in defence for team effectiveness in the game, but football team capacity is negatively affected by defence action indicators, for instance, allowed goals. In this research, the authors also classify technique based on game tactics, for example, attack and defence football technique. The aim of the next research (Modric, Versic, \& Sekulic, 2020) was to identify associations between aerobic fitness (AF) and game performance indicator (GPI) in elite football (Table 1). In this research, in order to determine the game performance, football technique is already classified according to the players' positions: central defenders' technique, fullbacks' technique, central midfielders' technique, wingers' technique, forwards' technique. Furthermore, the aim of the third research (Li, Ma, Goncalves, Gong, Cui, \& Shen, 2020) was to apply a state-of-the-art algorithm to the ranking of CSL teams and exploitation of key performance features in relation to match outcome based on massive match dataset. In order to determine the basic indicators of game performance, technique is classified according to the effectiveness of the technique in tactics: attacking technique, organizing technique, defensive technique (Table 1). In general, the mentioned research look at the efficiency of the technique, which is characterized by its compliance with the set tasks and the achievement of a high end result. 
SOCIETY. INTEGRATION. EDUCATION

Proceedings of the International Scientific Conference. Volume IV, May $28^{\text {th }}-29^{\text {th }}$, 2021. 456-467

Table 1 The Most Characteristic Classification of Football Technique in Database Science Direct (by the Authors)

\begin{tabular}{|c|c|c|}
\hline Author/s, Year & Research Aim & $\begin{array}{c}\text { Feature of Football Technique } \\
\text { Classification and Technique Elements }\end{array}$ \\
\hline $\begin{array}{l}\text { Zambom- } \\
\text { Ferraresi, Rios, \& } \\
\text { Lera-Lopez } \\
\text { (2018) }\end{array}$ & $\begin{array}{l}\text { The present study aims to } \\
\text { show that computer driven } \\
\text { mathematical and recent } \\
\text { statistical modelling } \\
\text { methods employing past } \\
\text { statistics data can be used to } \\
\text { provide European football } \\
\text { teams' managers with } \\
\text { additional information to } \\
\text { improve their hiring } \\
\text { decisions }\end{array}$ & $\begin{array}{l}\text { Classification feature - effectiveness } \\
\text { assurance in the game, where } \\
\text { effectiveness is increased by: } \\
\text { the assists, the saves made by the } \\
\text { goalkeeper, the number of precise passes } \\
\text { with respect to the total number of passes, } \\
\text { the shots on target and the number of } \\
\text { blocks, clearances, and interceptions. } \\
\text { Effectiveness is decreased by: defence } \\
\text { technique (shots conceded). } \\
\text { Classification feature - game tactics. } \\
\text { Attack football technique: } \\
\text { Shots, Shots on Target, Passes, Assists, } \\
\text { Crosses, Corners Taken, } \\
\text { Dribbles, Runs, Long Pass, Through Ball. } \\
\text { Defence football technique: } \\
\text { Shots, Tackles attempted, Tackled } \\
\text { possession retained, Recoveries, } \\
\text { Clearances, blocks, interceptions, Saves } \\
\text { made, Catches. }\end{array}$ \\
\hline $\begin{array}{l}\text { Modric, Versic, \& } \\
\text { Sekulic (2020) }\end{array}$ & $\begin{array}{l}\text { The aim of this study was to } \\
\text { identify associations } \\
\text { between aerobic fitness } \\
\text { (AF) and game } \\
\text { performance indicator } \\
\text { (GPI) in elite football }\end{array}$ & $\begin{array}{l}\text { Classification feature - specific playing } \\
\text { positions: } \\
\text { Central defenders' technique: tackling, } \\
\text { aerial duels, set pieces in defence, } \\
\text { interceptions. } \\
\text { Fullbacks technique: crosses, passes to the } \\
\text { penalty area, pressing. } \\
\text { Central midfielders' technique: } \\
\text { playmaking, key passes, finishing. } \\
\text { Wingers technique: pressing, dribbling, } \\
\text { finishing, counterattacking. Forwards } \\
\text { technique: shooting, finishing, pressing, } \\
\text { and dribbling. }\end{array}$ \\
\hline $\begin{array}{l}\text { Li, Ma, } \\
\text { Goncalves, Gong, } \\
\text { Cui, \& Shen, } \\
(2020)\end{array}$ & $\begin{array}{l}\text { The study was aimed to } \\
\text { apply a state-of-the-art } \\
\text { algorithm to the ranking of } \\
\text { CSL teams and exploitation } \\
\text { of key performance features } \\
\text { in relation to match } \\
\text { outcome based on massive } \\
\text { match data-set. }\end{array}$ & $\begin{array}{l}\text { Classification feature }- \text { technique } \\
\text { effectiveness in tactics: } \\
\text { Attacking technique: Shots and Shots on } \\
\text { target; } \\
\text { Organizing technique: Passes, Passes } \\
\text { success and Crosses; } \\
\text { Defensive technique: Tackles, } \\
\text { Interceptions and Clearances. }\end{array}$ \\
\hline
\end{tabular}


The selected research in the Google Scholar database reflect the classification of football technique in action both with and without the ball. The aim of the first research (Hughes, Caudrelier, James, Redwood-Brown, Donnelly, Kirkbride, \& Duschesne, 2012) was to use the unique opportunity of a large number of performance analysts coming together to discuss this problem and its application to soccer, and define sets of performance indicators for each position in soccer. In this research, football player technique is classified according to the players' position in attack and defence, which indicates the use of the game approach features in technique classification. Classification feature - specific playing positions in game tactics, where attack football technique:

Goalkeepers: shot stopping, recovery speed, save, punch. Full Backs: tackle, interception - anticipation, dribbling, running with the ball, clearance, defensive header. Centre Backs: passing, heading, running with the ball, support play, dribbling, crossing, shooting. Holding Midfield: passing, running with the ball, dribbling, support play, crossing, shooting, heading. Attacking Midfield: passing, running with the ball, dribbling, support play, crossing, shooting, heading. Wide Midfield: passing, running with the ball, dribbling, support play, crossing, shooting, heading. Strikers: tackle, pressing, opposition interception anticipation, heading.

Defence football technique: Goalkeepers: passing, throw, ball control with feet, kick, tackle. Full Backs: tackle, pressing, opposition interception anticipation, clearance, defensive header. Centre Backs: tackle, defensive header, pressing, opposition interception - anticipation, clearance. Holding Midfield: tackle, pressing, opposition interception - anticipation, heading. Attacking Midfield: tackle, pressing, opposition interception - anticipation, heading. Wide Midfield: tackle pressing, opposition cover full-back, interception - anticipation, heading.

Strikers: shooting, heading, reception, dribbling, passing, running with the ball, support play, crossing.

In turn, the next research (Drust, Atkinson, \& Reilly, 2012) has attempted to contextualise the available research that has attempted to evaluate the physiological demands of soccer on the basic-applied research continuum (Table 2). In this research, football player technique is classified according to the players' movements of moving (locomotion), i.e. the players' action without the ball. 
SOCIETY. INTEGRATION. EDUCATION

Proceedings of the International Scientific Conference. Volume IV, May $28^{\text {th }}-29^{\text {th }}$, 2021. 456-467

Table 2 The Most Characteristic Classification of Football Technique in Database Google Scholar (by the Authors)

\begin{tabular}{|c|c|c|}
\hline Author/s, Year & Research Aim & $\begin{array}{l}\text { Feature of Football Technique } \\
\text { Classification and Technique Elements }\end{array}$ \\
\hline $\begin{array}{l}\text { Drust, Atkinson, } \\
\text { \& Reilly (2012) }\end{array}$ & $\begin{array}{l}\text { This article has attempted to } \\
\text { contextualise the available } \\
\text { research that has attempted } \\
\text { to evaluate the physiological } \\
\text { demands of soccer on the } \\
\text { basic-applied research } \\
\text { continuum. }\end{array}$ & $\begin{array}{l}\text { Classification feature - players' } \\
\text { movements of moving: } \\
\text { Locomotion of players: move } \\
\text { backwards or sideways during play, a } \\
\text { shuffling gait, 'jockey' for position to } \\
\text { match the movements of their markers or } \\
\text { they 'spin away' from their markers into } \\
\text { clear space to secure a tactical advantage. } \\
\text { Runs: diagonal or angled to outwit } \\
\text { defensive lines, accelerate or decelerate } \\
\text { quickly and over short distances. }\end{array}$ \\
\hline $\begin{array}{l}\text { Atiq, Tangkudung } \\
\&\end{array}$ & $\begin{array}{l}\text { The research aimed to } \\
\text { develop basic technique } \\
\text { drill using Play-based } \\
\text { training for beginner } \\
\text { athletes in the age of 8-12 } \\
\text { years old in football schools } \\
\text { in Universitas Diponegoro } \\
\text { and Djarum Kudus. }\end{array}$ & $\begin{array}{l}\text { Classification feature - type of player } \\
\text { movements: } \\
\text { Basic technique: passing, dribbling, } \\
\text { heading, shooting. }\end{array}$ \\
\hline $\begin{array}{l}\text { Kokstejn \& } \\
\text { Musalek (2019) }\end{array}$ & $\begin{array}{l}\text { The aim of this study, } \\
\text { therefore, was to investigate } \\
\text { the relationship between } \\
\text { fundamental motor skills } \\
\text { and game specific motor } \\
\text { skills in elite young football } \\
\text { players. }\end{array}$ & $\begin{array}{l}\text { Classification feature - type of player } \\
\text { movements: } \\
\text { Fundamental motor skills: manipulative, } \\
\text { running, jumping, catching, throwing. } \\
\text { Game specific motor skills: receiving, } \\
\text { passing, shooting, and dribbling. }\end{array}$ \\
\hline $\begin{array}{l}\text { Lupo, Ungureanu, } \\
\text { Varalda \& Brustio } \\
\text { (2019) }\end{array}$ & $\begin{array}{l}\text { The present study aimed at } \\
\text { comparing the effects of } \\
\text { these two training } \\
\text { approaches } \\
\text { prepubescent } \\
\text { players' soccer } \\
\text { performances. }\end{array}$ & $\begin{array}{l}\text { Classification feature - type of player } \\
\text { skills: } \\
\text { Technical skills: passing, dribbling and } \\
\text { kicking, ball possession. } \\
\text { Tactical skills: running without the ball. }\end{array}$ \\
\hline $\begin{array}{l}\text { Maneiro, Casal, } \\
\text { Arda, \& Losada, } \\
\text { (2019) }\end{array}$ & $\begin{array}{l}\text { The aim of the present study } \\
\text { was to search for different } \\
\text { success models for the } \\
\text { corners in the FIFA World } \\
\text { Cup } 2014 \text { and FIFA } \\
\text { Women's World Cup } 2015 .\end{array}$ & $\begin{array}{l}\text { Classification feature }- \text { corner kick } \\
\text { efficiency: } \\
\text { Offensive performance: shot, shot } \\
\text { between the three posts, goal. }\end{array}$ \\
\hline
\end{tabular}


To improve the football technique classification theory by studying the fundamental skills and special skills in football (Yang, 2014), the author considers various features of football technique classification: type of difficulty of player movements, structure of player movements, type of player movements, specific playing positions in game tactics, game tactics. Classification feature - type of difficulty of player movements: fundamental techniques: kicking, catching and dribbling; special technique: pendulum passing, leg scissors interception. Classification feature - structure of player movements: single technique movements, combined techniques movement. Classification feature - type of player movements: with-ball techniques, without-ball techniques. Classification feature - specific playing positions in game tactics: technical movements of locations of forward and back players: with ball (kick, catch, dribble, head, scramble, intercept, throw-in), without ball (start, run, sudden stop, turn around, jump, foot work); technical movements of locations of goalkeepers: with ball (deflect ball, pounce/rush shot, punch set-up throw, kick), without ball (start, run, sudden stop, turn around, jump, foot work). Classification feature - game tactics: attack movements: catch technique, dribbling technique, passing technique; defence movements: snatch technique, intercept technique.

However, in the research on the development of basic technique drill using Play-based training for beginner athletes in the age of 8-12 years old in football schools (Atiq, Tangkudung, \& Mulyana, 2017), technique is classified according to the type of player movements - basic technique (Table 2).

Also, in the research on the relationship between fundamental motor skills and game specific skills in elite young soccer players (Kokstejn \& Musalek, 2019), the authors classify (Table 2) player technique according to the type of players' movements, distinguishing between fundamental and game specific motor skills.

In turn, in the research (Lupo, Ungureanu, Varalda \& Brustio 2019) on whether or not running technique is more effective than soccer-specific training for improving the sprint and agility performances with ball possession of prepubescent soccer players, the authors classify technique taking into account the type of player training - technical and tactical training (Table 2). However, in the research (Maneiro, Casal, Arda, \& Losada, 2019) “Application of multivariant decision tree technique in high performance football: the female and male corner kick", the authors have identified corner kick efficiency features during attack.

By classifying according to the type of player movements (Nosaeva \& Mihajlov, 2020), a distinction can be made between basic technique methods of movement and basic technique methods in action with the ball. Classification feature - type of player movements: basic technique of movement: running, stopping at a step, jumping with a push of one leg, turning towards the supporting leg; basic technique in action with the ball: receiving the ball (carrying out a body 
link towards the ball and yielding movement, stopping a falling ball after a rebound - covering the ball, dribbling changes in speed and direction of movement with the ball, sequence of actions with the ball, hitting the ball with the head and throwing in the ball with hands - whipping with legs, torso and arms, hitting on the ball with a leg - rigid fixation of the leg in all joints at the moment of impact. Kicks on the ball: with a swing and a whip; without a swing; without swing and whip). Hits on the ball with the middle of the instep and the inside of the foot, dribbling the ball with the middle of the instep, stopping the falling ball with the sole, "removing the ball with the inside of the instep", stopping the rolling ball with the inside of the foot feints "false stop of the ball", "feint with the torso", "false swing", hitting the ball flying towards the middle of the forehead.

Taking into account the previously defined features of classification (type of difficulty of player movements, structure of player movements, type of player movements, specific playing positions in game tactics, game tactics, type of training), they characterize technique as a football skill, which has a defined football skill content and can be broadly referred to as the technique approach.

However, if technique is classified according to its efficiency and effectiveness (effectiveness assurance in game, corner kick efficiency, technique effectiveness in tactics), i.e. suitability and relevance to the achievement of the aim, it is characterized by the game approach.

The development of football technique classification can be described as a gradual transition from the technique approach to the game approach. Using the technique approach, football technique was mainly grouped according to the player's action with or without the ball, the level of difficulty of the technique element, the players' role and the player's action on the spot or in motion.

\section{Discussion and Conclusions}

The results of the research show that technique classification in the game approach is mainly the application of the developed classifications (Horton et al., 2014) in order to obtain quantitative measurements of performance, for example, indicators assuring effectiveness in the game (Zambom-Ferraresi et al., 2018), corner kick efficiency (Maneiro et al., 2019), technique effectiveness in tactics (Li et al., 2020). Thus, providing a qualitative assessment of movements and the identification of the most important influencing factor (Knudson, 2013) in order to further improve the training process and the performance of football players.

From the point of view of sport science, the results of the research show an explanation of the essence of the game approach in football technique classification in the context of football technique efficiency and effectiveness. Where the technique effectiveness is an integral indicator, as it is determined by 
its efficiency, stability, variability, economy, and minimal tactical informativeness to the opponent.

Research limitations: a systematic literature search and review was performed by selecting two databases - Science Direct and Google Scholar. The selected keywords and the order of their application can be considered as limitations to systematic search and they provided the previously mentioned results. The authors assume that if they had used other databases and other keywords and / or used them in a different order, the results of the research would have been different. The research can be continued by conducting a systematic literature search and review, selecting other scientific databases.

Main conclusions: initially, football technique was mainly grouped by taking into account the player's actions with or without the ball, the level of difficulty of the technique element, the role of the players and the player's actions on the spot or in motion. As football develops, football technique is classified by taking into account the effectiveness of its application in specific tactical situations.

The development trends of football technique classification also reflect the implementation of didactic principles of football technique acquisition, for instance, gradual increase of difficulty, ensuring the interrelation and unity of the competition activity structure and training activity structure.

\section{References}

Andersson, H., Ekblom, B., \& Krustrup, P. (2008). Elite football on artificial turf versus natural grass: movement patterns, technical standards, and player impressions. Journal of sports sciences, 26(2), 113-122. https://doi.org/10.1080/02640410701422076

Atiq, A., Tangkudung, J. \& Mulyana. (2017). Development of basic techniques procurement model a bol soccer athletes based play for beginners ages 8-12 years. Journal of Indonesian Physical Education and Sport, 3(2), 113-115. Retrieved from http://journal.unj.ac.id/unj/index.php/jipes/article/view/6077/4423

Bangsbo J. (1994). The physiology of soccer-with special reference to intense intermittent exercise. Acta physiologica Scandinavica. Supplementum, 619, 1-155. PMID: 8059610

Bartlett, R. (2014). Introduction to sports biomechanics: analysing human movement patterns. Third edition. London: Routledge.

Booth, A., Sutton, A., \& Papaioannou, D. (2016). Systematic approaches to a successful literature review. Los Angeles, CA: Sage.

Bös, K., Mechling, H. (1983). Dimensionen Sportmotorischer Leistungen. Hofmann, Schorndorf.

Bradley, P. S., O’Donoghue, P., Wooster, B., \& Tordoff, P. (2007). The reliability of Prozone MatchViewer: A video-based technical performance analysis system. International Journal of Performance Analysis in Sport, 7, 117-129. https://doi.org/10.1080/ 24748668.2007.11868415

Bradley, P. S., Carling, C., Archer, D., Roberts, J., Dodds, A., Di Mascio, M., Paul, D., Diaz, A. G., Peart, D., \& Krustrup, P. (2011). The effect of playing formation on high-intensity 
running and technical profiles in English FA Premier League soccer matches. Journal of sports sciences, 29(8), 821-830. https://doi.org/10.1080/02640414.2011.561868

Drust, B., Atkinson, G. \& Reilly, T. (2012). Future perspectives in the evaluation of the physiological demands of soccer. Sports Medicine, 36, 783-805. DOI: https://doi.org/10.2165/00007256-200737090-00003

Esposito, G., Ceruso, R. \& Elia, F.D. (2019). The importance of a technical-coordinative work with psychokinetic elements in the youth sectors of soccer academies. Journal of Physical Education and Sport, 19(5). 1843. DOI: 10.7752/jpes.2019.s5272

Gonzalez-Villora, S., Serra-Olivares, J., Pastor-Vicedo, J.C. \& Costa, I.T. (2015). Review of the tactical evaluation tools for youth players, assessing the tactics in team sports: football. SpringerPlus, 4(663). 1. DOI: https://doi.org/10.1186/s40064-015-1462-0

Horton M., Gudmundsson J., Chawla, S., Estephan, J. (2014). Classification of passes in football matches using spatiotemporal data. arXiv:1407.5093, Retrieved from https://arxiv.org/pdf/1407.5093.pdf

Hughes, M., Caudrelier, T., James, N., Redwood-Brown, A., Donnelly, I., Kirkbride, A. \& Duschesne, C. (2012). Moneyball and soccer - an analysis of the key performance indicators of elite male soccer players by position. Journal of Human Sport and Exercise, 7(2), 402-411. DOI: http://dx.doi.org/10.4100/jhse.2012.72.06

Knudson, D. V. (2013). Qualitative Diagnosis of Human Movement: Improving Performance in Sport and Exercise. Human Kinetics.

Kokstejn, J. \& Musalek, M. (2019). The relationship between fundamental motor skills and game specific skills in elite young soccer players. Journal of Physical Education and Sport, 19(1), 249-253. DOI: 10.7752/jpes.2019.s1037

Lees, A. (2002). Technique analysis in sports: a critical review. Journal of Sports Sciences, 20, 813 - 828. https://doi.org/10.1080/026404102320675657

Li, Y., Ma, R., Goncalves B., Gong, B., Cui, Y. \& Shen, Y. (2020). Data-driven team ranking and match performance analysis in Chiniese Football Super League. Chaos, Solitons \& Fractals, 141(110330), 2. Retrieved from https://www.sciencedirect.com/science/article/ $\mathrm{pii} / \mathrm{S} 0960077920307256$

Lupo, C., Ungureanu, A.N., Varalda, M. \& Brustio, P.R. (2019). Running technique is more effective than soccer-specific training for improving the sprint and agility performances with ball possession of prepubescent soccer players. Biology of Sport, 36(3), 245-250. DOI: 10.5114/biolsport.2019.87046

Maneiro, R., Casal, C.A., Arda, A. \& Losada, J.L. (2019). Application of multivariant decision tree technique in high performance football: The female and male corner kick. PLoS ONE, 14(3): e0212549, 2-5. Retrieved from https://doi.org/10.1371/journal.pone.0212549

Mitchell, J.H., Haskell, W.L. \& Raven, P.B. (1994). Classification of Sports. American College of Cardiology and American College of Sport Medicine, 24(4), 864-866. Retrieved from https://www.jacc.org/doi/pdf/10.1016/0735-1097\%2894\%2990841-9

Modric, T., Versic, S. \& Sekulic, D. (2020). Aerobic fitness and game performance indicators in professional football players; playing position specifics and associations. Heliyon, 6: e05427. 2. https://doi.org/10.1016/j.heliyon.2020.e05427

Nosaeva, M.M. \& Mihajlov, A.Ju. (2020). Tehnicheskaja podgotovka futbolistov na jetape nachal'noj podgotovki. Fizicheskaja kul'tura, sport, turizm:problemy i perspektivy, 3(28), 63-64. Retrieved from https://cyberleninka.ru/article/n/tehnicheskaya-podgotovkafutbolistov-na-etape-nachalnoy-podgotovki

Ozoliṇš, N. (1982). Mērkțiecīgs treniņš. Rīga: Avots. 
Sokal, R. (1974). Classification: Purposes, Principles, Progress, Prospects. Science, 185(4157), 1115-1123. Retrieved from http://www.jstor.org/stable/1738359

Yang, Z. (2014). Study on classification of football techniques and the analysis on factors influencing football techniques. An Indian Journal of Bio Technology. 13035-13036. Trade Science inc. Retrieved from https://www.tsijournals.com/articles/study-onclassification-of-football-techniques-and-the-analysis-on-factors-influencing-footballtechniques.pdf

Zahradnik, D., \& Korvas, P. (2017). The introduction into sports training. Brno: Masaryk University.

Zambom-Ferraresi, F., Rios, V. \& Lera-Lopez, F. (2018). Determinants of sport performance in European football: What can we learn from the data? Decision Support Systems, 114, 24. Retrieved from https://www.sciencedirect.com/science/article/pii/S0167923618 301350 